\title{
ПРЕПАРАТИВНОЕ ВЫДЕЛЕНИЕ МЕТИЛАРАХИДОНАТА МЕТОДОМ ЖИДКОСТНОЙ КОЛОНОЧНОЙ ХРОМАТОГРАФИИ
}

Арахидоновая кислота, эйкоза-цис-5,8,11,14-тетраеновая кислота (далее $20: 4)$, является субстратом в биосинтезе биологически активных соединений - простагландинов (ПГ). Она в небольших количествах содержится в живом организме в составе липидов, например, в липидах надпочечников ее содержание не превышает 3-8\%. Для выделения 20:4 кислоты высокой степени чистоты требуется ряд операций: выделение смеси липидов из ткани с последующим гидролизом, обогащение полученной смеси свободных жирных кислот целевым продуктом методом низкотемпературной кристаллизации и окончательная очистка полученного концентрата арахидоновой кислоты хроматографическими методами $\left[{ }^{1-3}\right]$.

В настоящей работе предложен модифицированный на основе [ $\left.{ }^{4}\right]$ препаративный способ для разделения концентрата 20:4 кислоты (полученной путем низкотемпературной кристаллизации) в виде метиловых эфиров на силикагеле, импрегнированном нитратом серебра.

\section{Экспериментальная часть}

Хроматографирование проводилось в стеклянной колонке, снабженной рубашкой для термостатирования. В колонку вводился в виде суспензии в ацетоне предварительно активированный в течение 10 ч при $120^{\circ} \mathrm{C}$ силикагель. После оседания силикагеля содержимое колонки промывалось под давлением инертного газа $0,1 \kappa 2 / \mathrm{cm}^{2} 500 \mathrm{M}$ ацетона и 500 мл ащетонитрила. Колонка, защищенная от света, импрегнировалась $10 \%$-ным раствором нитрата серебра в ацетонитриле (скорость 0,5-0,6 мл/мин). Импрегнированный силикагель промывался 150 мл диэтилового эфира (ДЭЭ), 400 мл смеси ДЭЭ и н-гексана $(1: 1)$, а затем 1000 мл н-гексана. После этого в колонку вводилось 25 г метилированного концентрата в гексане, и колонка подвергалась термостатированию в течение 1 ч.

Хроматографирование проводилось при избранной температуре колонки со смесью н-гексан-ДЭЭ (градиент ДЭЭ $0-100 \%$ об.) под избыточным давлением инертного газа $0,1-0,2 \kappa 2 / \mathrm{cm}^{2}$. Фракции (скорость 8-10 мл/мин) отбирались по $500 \mathrm{M}$, растворитель выпаривался из элюата в ротационном испарителе под вакуумом при $35^{\circ}$. Фракцин анализировались методом ГЖХ на хроматографе Хром-4.

\section{Обсуждение результатов}

Разделению подвергались смеси эфиров кислот, содержащие 40-65\% метиларахидоната (рис. 1). При помощи эталонных соединений были идентифицированы пики эфиров $16: 0,18: 1,18: 2,18: 3,20: 0,20: 4$ 


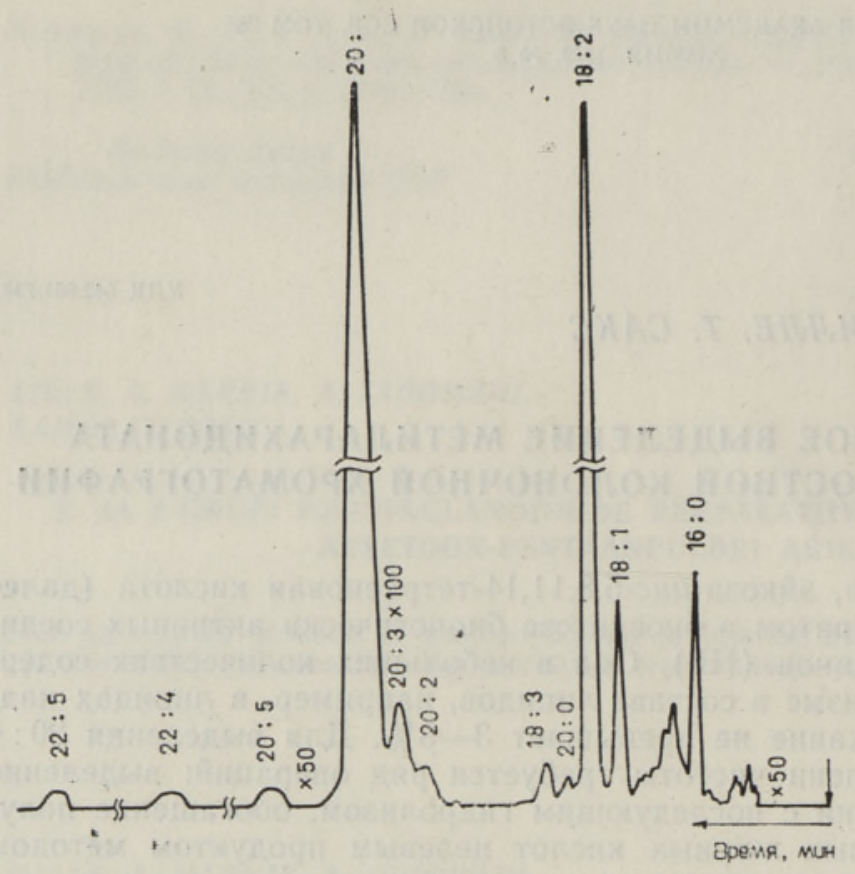

Рис. 1. Газовая хроматограмма исходного концентрата метиларахидоната (содержание основного компонента $65 \%$ ). Цифры у пиков указывают количество атомов углерода и двойных связей в молекуле кислоты. Условия анализа: колонка $350 \times 0,3 \mathrm{cM}$, жидкая фаза - $3 \%$ поли-1,4бутандиолсукцината на хезасорбе $A W-H M D S$ (0,25-0,36 мм), температура колонки $220^{\circ} \mathrm{C}$, газноситель - гелий, входное давление $1,2 \kappa 2 / c .^{2}$, пламенно-ионизационный детектор.

кислот. По удерживанию эфиров в газохроматографической колонке и в колонке с $\mathrm{Ag}^{+}$-силикагелем установлены пики эфиров $20: 3,20: 5,22: 4$ и $22: 5$ кислот.

На разделительную способность колонки, зависящую от устойчивости комплекса $\mathrm{Ag}^{+}$- элюат, существенное влияние оказывает также температура колонки и полярность элюента. Результаты экспериментов показали, что при низкой температуре колонки $\left(0^{\circ}\right)$ следует использовать более полярный состав элюата $н$-гексан-ДЭЭ, при температуре колонки $15^{\circ}$ - менее полярный элюент. Поэтому препаративное разделение обычно проводится при температуре $15^{\circ}-$ в этом случае не требуется холодильной установки и меньше расход ДЭЭ.

В комплексообразовании с $\mathrm{Ag}^{+}$участвуют все кратные связи элюата [5], поэтому разделение эфиров жирных кислот происходит за счет различия в степени насыщенности в разделяемых молекулах (рис. 2). Эфиры с одинаковым числом кратных связей элюируются одновременно, несмотря на разницу в длине углеродной цепи.

При введении в колонку 25 г разделяемой смеси было выделено 10,8 ح метиларахидоната (чистота не менее $96,9 \%$ ) - $83 \%$ от его исходного количества в концентрате. Фракции, в которых содержание целевого вещества ниже требуемого $(75-90 \%)$, подвергались повторному хроматографированию. Общие потери метиларахидоната не превышали $1,5 \%$, при этом они не связаны с хроматографическим процессом.

В выделенном продукте содержится ничтожное количество эфиров $18: 1$ и 18:2 кислот. Следы эфира 18:3 кислоты и сопряженных структур (по данным УФ-спектра) обнаружены не были. Спектр ЯМР ${ }^{13} \mathrm{C}$ полученного метиларахидоната приведен на рис. 3.*

Показателем чистоты полученного метиларахидонага является степень разделения эфиров 20:3 и 20:4 кислот, так как их соотношение

* Спектры снималисьь в секторе физики Института кибернетики АН Эстонской ССР. 
определяет соотношение продуктов биосинтеза ПГ $E_{1}$ и ПГ $E_{2}$. В оптимальных условиях опыта эта пара разделяется достаточно глубоко (рис. 2).

Таким образом, примерно 170-кратное увеличение масштаба разделения искусственно составленной смеси эфиров кислот [ $\left.{ }^{4}\right]$ позволяет препаративно выделить из обогащенной смеси эфиров липидных кислот достаточно чистый метиларахидонат.

\section{Вывод}

Разработан препаративный метод выделения чистого метиларахидоната из обогащенной смеси липидных кислот путем жидкофазного хроматографирования на колонках, содержащих импрегнированный нитратом серебра силикагель.

\section{Л И Т Е Р А Т У Р А}

1. Hilditch, T. The chemical constitution of natural fats. New York, 1956, p. 570622.

2. De Vries, B. Quantitative separation of higher fatty acid methyl esters by adsorption chromatography on silica impregnated with silver nitrate. - J. Amer. Chem. Soc. 1963 , v. 40 , p. $184-186$.

3. Сакс Т., С амель Н., Ягомяги А., Иванов А. Разделение метиловых эфиров высших жирных кислот методом препаративной газовой хроматографии. II. Препаративное разделение. - Изв. АН ЭССР. Хим., 1978, т. 27, № 4, с. 289290 .

4. S te in, R. A., S l a w s o n, V. Investigation of adsorption of unsaturated fatty acid methyl esters on silicic acid-silver nitrate. - Analyt. Chem., 1968, v. 40, N 13, p. $2017-2020$.

5. Гуха О. К., Янак Я. Применение комплексов металлов с переносом заряда в хроматографии органических соединеннй. - Успехи химии, 1973, т. 42, № 9, c. $1708-1727$.

Ннститут химии

Академии наук Эстонской ССР

Поступила в редакцию 15/XII 1978

\section{A. JAGOMAGI, O. LILLE, T. SAKS}

\section{METUOLARAHIDONAADI PREPARATIIVNE PUHASTAMINE VEDELIK-KOLONNKROMATOGRAAFIAMEETODIL}

On esitatud arahidoonhappe kontsentraadi puhastamise meetod, mille puhul kontsentraati kromatografeeritakse metüülestrina hõbenitraadiga immutatud silikageeli kolonnis ning elueeritakse $n$-heksaan ${ }^{*}$ ia dietüüleetri seguga, tỗstes viimase sisaldust astmeliselt.

\section{PREPARATIVE SEPARATION METHOD OF METHYLARACHIDONATE BY LIQUID COLUMN CHROMATOGRAPHY}

The mixture of methyl esters of higher fatty acids concentrated relative to the arachidonic acid methyl ester was separated by a column chromatography method on $\mathrm{Ag}^{+}$-silicagel. Elution succeeded at $0{ }^{\circ} \mathrm{C}$ or at $+115^{\circ} \mathrm{C}$ under the pressure of $0.1-0.2 \mathrm{~kg} / \mathrm{cm}^{2}$, using stepped gradient of ethyl ether in the hexane. A purity of $96-97 \%$ of methylarachidonate was achieved. 